\title{
EXTRACTION AND CHARACTERIZATION OF CELLULOSE AND MICROCRYSTALLINE CELLULOSE (MCC) FROM Marantochloa cuspidata LEAVES
}

\author{
E. R, Udo ${ }^{1 *}$, T. U. Onuegbu ${ }^{1}$ and U. D. Akpabio ${ }^{2}$ \\ ${ }^{1}$ Department of Pure and Industrial Chemistry, Nnamdi Azikiwe University, Awka \\ ${ }^{2}$ Department of Chemistry, University of Uyo \\ *Corresponding author- eru4life21@ yahoo.com and tu.onuegbu@unizik.edu.ng /+2348035089803 \\ Received 10 July 2020; accepted 06 October 2020, published online 03 November 2020
}

\begin{abstract}
Microcrystalline cellulose (MCC) from Marantochloa cuspidata leaves were isolated and characterized. The physicochemical properties of the leaves were investigated. The functional groups analyses were carried out using Fourier Transform Infrared (FTIR) Spectroscopy and the crystalline structure were investigated using Xray Diffraction (XRD). The morphology and thermal stabilities were investigated using Scanning Electron Microscope (SEM) and Thermo Gravimetric Analysis (TGA) respectively. The moisture content of the leaves was $7.16 \pm 0.12 \%$. From FTIR, the spectra showed that the hemicelluloses and lignin were removed from the extracted cellulose. The peaks at $1733 \mathrm{~cm}^{-1}$ and $1375 \mathrm{~cm}^{-1}$ in the spectra of $M$. cuspidata leaves which were attributed to $\mathrm{C}=\mathrm{O}$ stretching and $\mathrm{C}-\mathrm{O}$ out-of plane stretching vibration of the hemicelluloses and lignin disappeared in the spectra of cellulose and MCC. XRD showed that the MCC produced is cellulose I polymorph. The SEM structures showed the microfibrils of the extracts to be crystallites. Cellulose and MCC were shown to have good thermal stability with a degradation temperature of $250^{\circ} \mathrm{C}$ and $260^{\circ} \mathrm{C}$ respectively.
\end{abstract}

Keywords: Microcrystalline cellulose, Marantochloa cuspidata, physicochemical properties FTIR, XRD, SEM, $T G A$.

\section{INTRODUCTION}

Cellulose is the most abundant polymer in nature, primarily composed of cell wall of plants, which gives support and rigidity to their structure. It is renewable and biodegradable. It exists in woods, cotton, hemp, husks, straws, sugarcane bagasse and many other plant based materials. Plant derived cellulose is usually found in a mixture with hemicellulose, lignin, pectin and other chemical substances while bacterial cellulose is quite pure, has a much higher water content and higher tensile strength due to higher chain lengths [1].

Native cellulose consists of amorphous and crystalline regions. The amorphous regions have lower density compared to the crystalline regions, so when cellulose fibres are subjected to harsh acid or alkali treatment, the amorphous regions breaks up, releasing the individual crystallites which may be microcrystalline cellulose or nano-crystalline cellulose depending on the condition of hydrolysis. These amorphous zones are regions in which the hydroxyl groups are more readily available for reaction than in the more highly ordered crystalline areas, which are less reactive [2]. Cellulose obtained from different origins and hydrolysis conditions differ in crystallinity, moisture content, surface area, porous structure, particle size and molecular weight [3] [4]. The ratio of amorphous cellulose to crystalline cellulose is called degree of crystallinity which depends upon the species and pretreatment of the sample [5]. Crystalline cellulose is much stronger and stiffer, it is considered to be a better reinforcing material than amorphous or the native cellulose itself [6].

Many researchers have extracted and studied the properties of crystallites such as microcrystalline cellulose (MCC) from various plant based materials. Thermally stable rice husk microcrystalline cellulose as adsorbent was studied [7]. Muli bamboo (Melocanna baccifera) as a new source of microcrystalline cellulose was investigated [8]. The cellulose and $\alpha$-cellulose yields from original material were $62.5 \%$ and $54.8 \%$ respectively. The prepared MCC was characterized by FTIR, SEM, TGA and XRD. Results from these analyses indicate that the muli bamboo can be used as a green source of MCC. Physicochemical properties of microcrystalline cellulose from agricultural waste, orange mesocarp were investigated [9]. The results obtained showed that the yield of $\alpha$-cellulose from the orange mesocarp was $62.5 \%$ and that of microcrystalline cellulose $25.3 \%$. Microcrystalline cellulose from bagasse and rice straw using acid hydrolysis was investigated [10]. The different characteristics of prepared microcrystalline cellulose were determined and are found to be comparable with the characteristics of commercially available microcrystalline cellulose and the specifications given by Indian Standards. Cellulose and microcrystalline cellulose from rice straw and banana plant waste harvested in Egypt were investigated [11]. The results indicated higher $\alpha$ cellulose content, $66.2 \%$, in case of acid-alkaline treatment for rice straw compared to $64.7 \%$ in case of alkaline-acid treatment. MCC was prepared and characterized from tea waste by acid hydrolysis [12]. 
Microcrystalline cellulose (MCC) is a granular powder product with a size of about $10 \mu \mathrm{m}$, obtained from the hydrolysis of the natural cellulose in an acidic medium, making the molecular weight reduced to a certain range. It is white, porous, tasteless, odourless, crystalline powder extracted from hydrolysis of native cellulose with diluted mineral acids or enzymolysis to produce alpha-cellulose, which is partially depolymerized and purified to obtain MCC. The MCC can be synthesized using mineral acids such as $\mathrm{H}_{2} \mathrm{SO}_{4}, \mathrm{HCl}$ and $\mathrm{HBr}$ as well as ionic liquids. The role of these reagents is to destroy the amorphous regions leaving the crystalline domain [13]. Mild acid gives microcrystalline cellulose (MCC) while strong acid treatment gives nanocrystalline cellulose. The results of FTIR, XRD and SEM analyses of microcrystalline cellulose (MCC) fibers from corncorbs at various alkaline treatments were compared [14].

MCC is mainly used in the pharmaceutical industry as excipient, and in food industry as additives. The leaves of Marantochloa cuspidata are widely used in wrapping foods such as kola nut and moi-moi in African Communities.

\section{MATERIALS AND METHODS}

\section{Raw Materials}

The fresh leaves of Marantochloa cuspidata were harvested from a farmland in Nnung Eboh in Nsit lbom L.G.A of Akwa lbom State. It was washed, airdried, ground and the ground sample was stored in an air-tight container prior its usage. The dried samples of the leaf are shown in Figure 1.

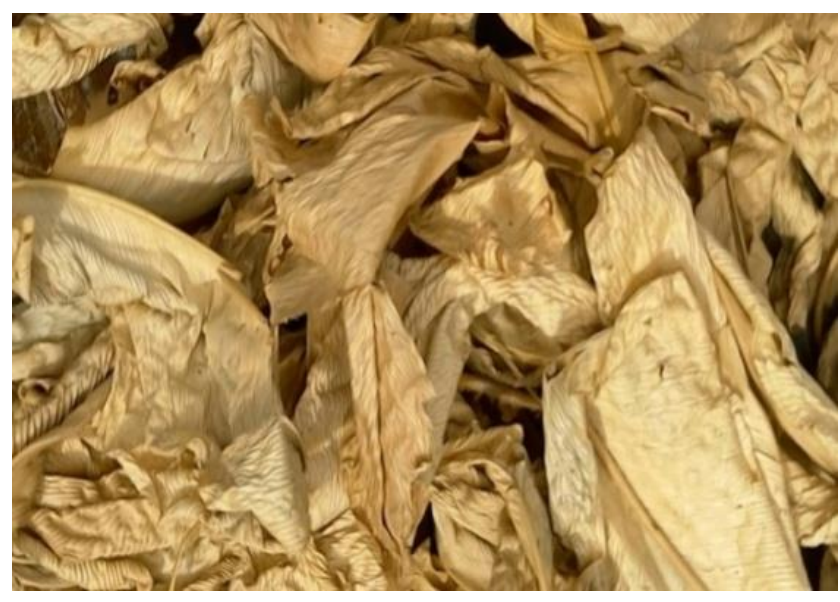

Figure 1: The dried leaves of Marantochloa cuspidata

\section{Extraction of cellulose}

Cellulose was prepared by the delignification process of sodium hypochlorite. $50 \mathrm{~g}$ of the air-dried sample was measured and $1.2 \mathrm{~L}$ of sodium hypochlorite was added. This was properly corked and left for $24 \mathrm{hrs}$ at room temperature, after which was filtered and washed thoroughly with deionized water before $500 \mathrm{~mL}$ of $18 \% \mathrm{NaOH}$ and $500 \mathrm{~mL}$ of $50 \mathrm{w} / \mathrm{w} \%$ hydrogen peroxide were added and left overnight. This was done to get rid of hemicelluloses and the residual lignin. Bleaching treatment further helps to remove most of the lignin.

Thereafter, the mixtures were filtered, washed with deionized water and was dried in an oven at a temperature of $80^{\circ} \mathrm{C}$ for an hour. The weight of the extracted cellulose and MCC were obtained, hence, the percentage yields calculated.

\section{Extraction of microcrystalline cellulose from cellulose fibres}

The cellulose obtained was acid hydrolyzed using $100 \mathrm{~mL}$ of $25 \mathrm{wt} \% \mathrm{H}_{2} \mathrm{SO}_{4}$ at room temperature for 40 minutes.

\section{FTIR Spectroscopy}

This was carried out using FTIR spectroscopy (PerkinElmer, U.S.A). Infrared spectra of raw leaves, cellulose and microcrystalline cellulose from Marantochloa cuspidata between $4000 \mathrm{~cm}^{-1}$ to $600 \mathrm{~cm}^{-}$ ${ }^{1}$ were recorded at a resolution of $4 \mathrm{~cm}^{-1}$.

\section{X-ray Diffractometer}

The X-ray diffraction patterns of raw leaves, cellulose and MCC were analyzed with a Siemens D 5000 Diffractometer, using $\mathrm{CuK}$ radiation $\left(\mathrm{X}=1.5418^{\circ} \mathrm{A}\right)$ at a $40 \mathrm{KV}$ and a current of $30 \mathrm{~mA}$, making measurements every $0.02^{\circ}$ for $6 \mathrm{~s}$. The data was acquired in a $2 \theta$ range from $2^{\circ}$ to $60^{\circ}$.

The crystallinities of all samples were determined [15].

Crystallinity $=\left[\mathrm{I}_{\text {cry }}-\mathrm{I}_{\mathrm{am}} / \mathrm{I}_{\text {cry }}\right] \times 100$

where $\mathrm{I}_{\mathrm{am}}$ represents the amorphous material.

\section{Scanning Electron Microscope}

The surface morphologies of the samples were determined using Scanning Electron Microscope (JOEL JSM 610 LA model) at magnification of 1000x 1265. The differences in morphologies were obtained.

\section{Determination of Thermal Property using TGA}

A Mettler Toledo (model TGA/SDTA851e) thermogravimetric analyser was used to characterize the thermal stability of the samples. $2 \mathrm{mg}$ of each of them was placed in an aluminium pan and heated from 30 to $600^{\circ} \mathrm{C}$ at a heating rate of $10^{\circ} \mathrm{C} / \mathrm{min}$. All measurements were performed under a nitrogen atmosphere.

\section{RESULTS AND DISCUSSION}

The Percentage yields of extracted cellulose and MCC were $49 \%$ and $23 \%$ respectively. The results of 
physicochemical analysis of Marantochloa cuspidata Leaves are shown in Table 1.

Table 1: Physicochemical Characteristics of Marantochloa cuspidata Leaves

\begin{tabular}{ll}
\hline Parameters & Results (\%) \\
\hline Moisture content & $7.16 \pm 0.32$ \\
Cold water solubility & $84.33 \pm 0.44$ \\
Hot water solubility & $85.33 \pm 0.16$ \\
$1 \% \mathrm{NaOH}$ solubility & $72.83 \pm 0.60$ \\
$18 \% \mathrm{NaOH}$ solubility & $48.00 \pm 3.51$ \\
$1: 2$ Ethanol : Benzene solubility & $79.83 \pm 2.17$ \\
\hline
\end{tabular}

The molecular structures of the different samples were characterized by FTIR spectroscopy in the region of 4000 to $400 \mathrm{~cm}^{-1}$ (as shown in Figures $2 \mathrm{a}, \mathrm{b} \& \mathrm{c}$ ). The prominent peak of $1733 \mathrm{~cm}^{-1}$ in the spectrum of raw marantochloa cuspidata leaves is attributed to the $\mathrm{C}=\mathrm{O}$ stretching of acetyl group and uronic ester group of the hemicelluloses or the ester linkage of the carboxylic group of the ferulic and p-coumaric acids of lignin and/or hemicelluloses. However, this peak disappeared in the spectra of extracted cellulose and MCC and this is due to the removal of most of the hemicelluloses after alkali treatment.

\section{FTIR analyses}

Figure 2a: FTIR of raw sample from Marantochloa cuspidata leaf.

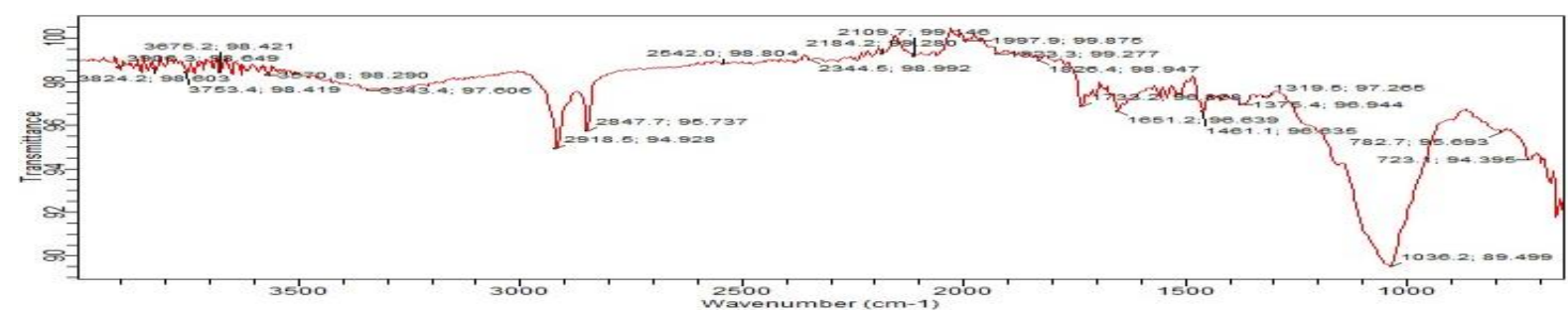

Figure 2b: FTIR of cellulose sample from Marantochloa cuspidata leaf.

Figure 2c: FTIR of MCC sample from Marantochloa cuspidata leaf.

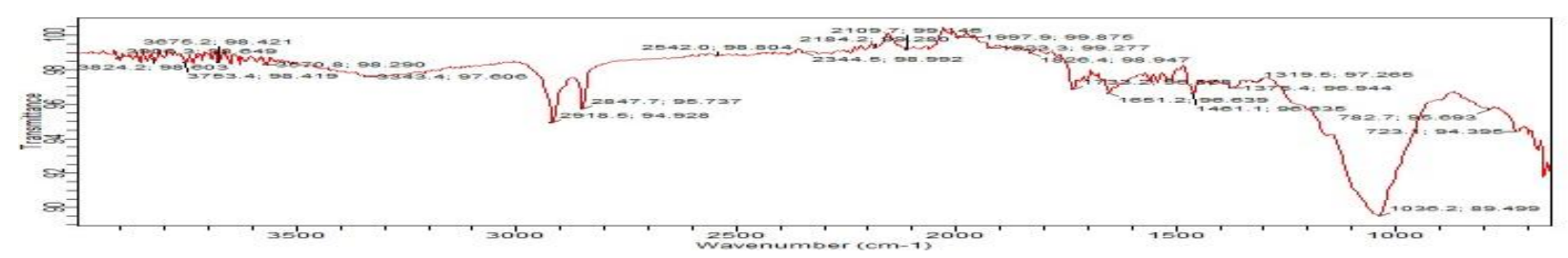




\section{X-ray Diffraction Analysis}

The X-ray Diffraction results of raw leaves of Marantochloa cuspidata, cellulose and MCC are shown in Figures $3 a, b$ \& c.

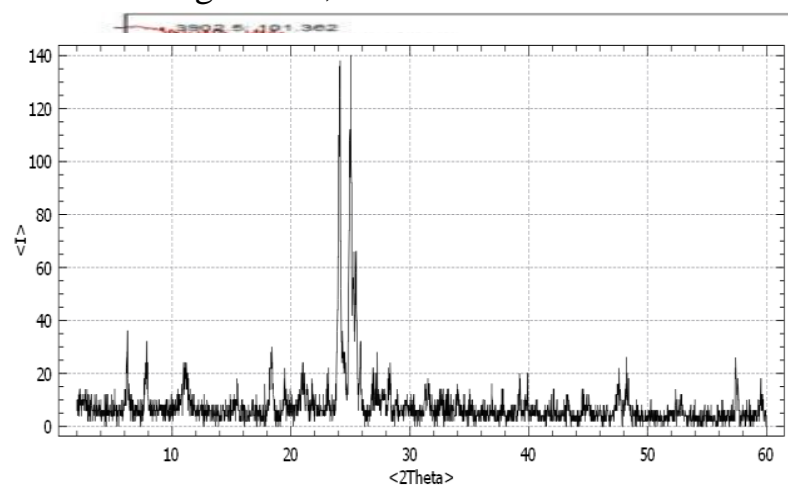

Figure 3a: X-ray diffraction pattern of Marantochloa cuspidata.

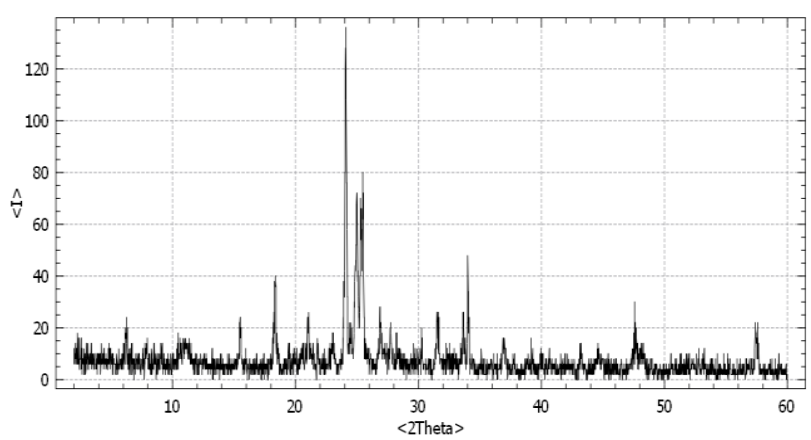

Figure 3b: X-ray diffraction pattern of cellulose from Marantochloa cuspidata.

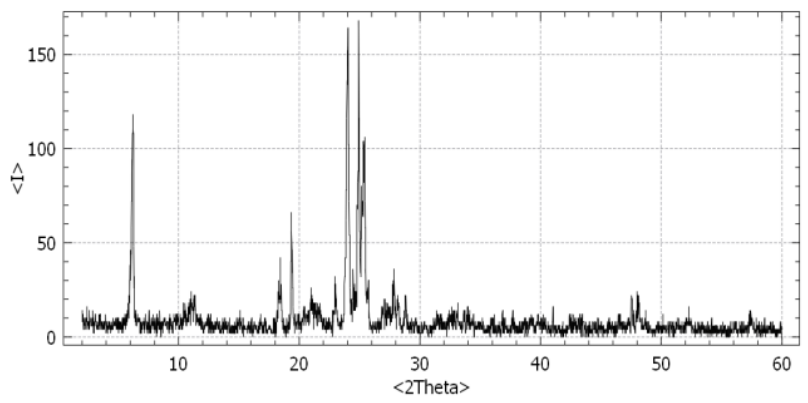

Figure 3c: X-ray diffraction pattern of microcrystalline cellulose.

The results of XRD of the leaves, cellulose and microcrystalline cellulose of Marantochloa cuspidata are shown in Figures $3 \mathrm{a}, \mathrm{b} \& \mathrm{c}$. These samples exhibited peaks around $2 \theta=18^{\circ}$ and $24.5^{\circ}$ while cellulose alone showed a peak around $2 \theta=35^{\circ}$, indicating a typical cellulose 1 structure. It can be seen that in all samples the peak around $24.5^{\circ}$ was more prominent but more intense in MCC indicating higher crystallinity. The crystallinity of prepared raw leaves, cellulose and MCC were $25.15 \%, 28.63 \%$ and $35.2 \%$ respectively.

\section{Morphological analysis}

The electron micrographs of the leaves, cellulose and MCC from Marantochloa cuspidata are shown in Figures $4 \mathrm{a}, \mathrm{b} \& \mathrm{c}$ at different magnifications.
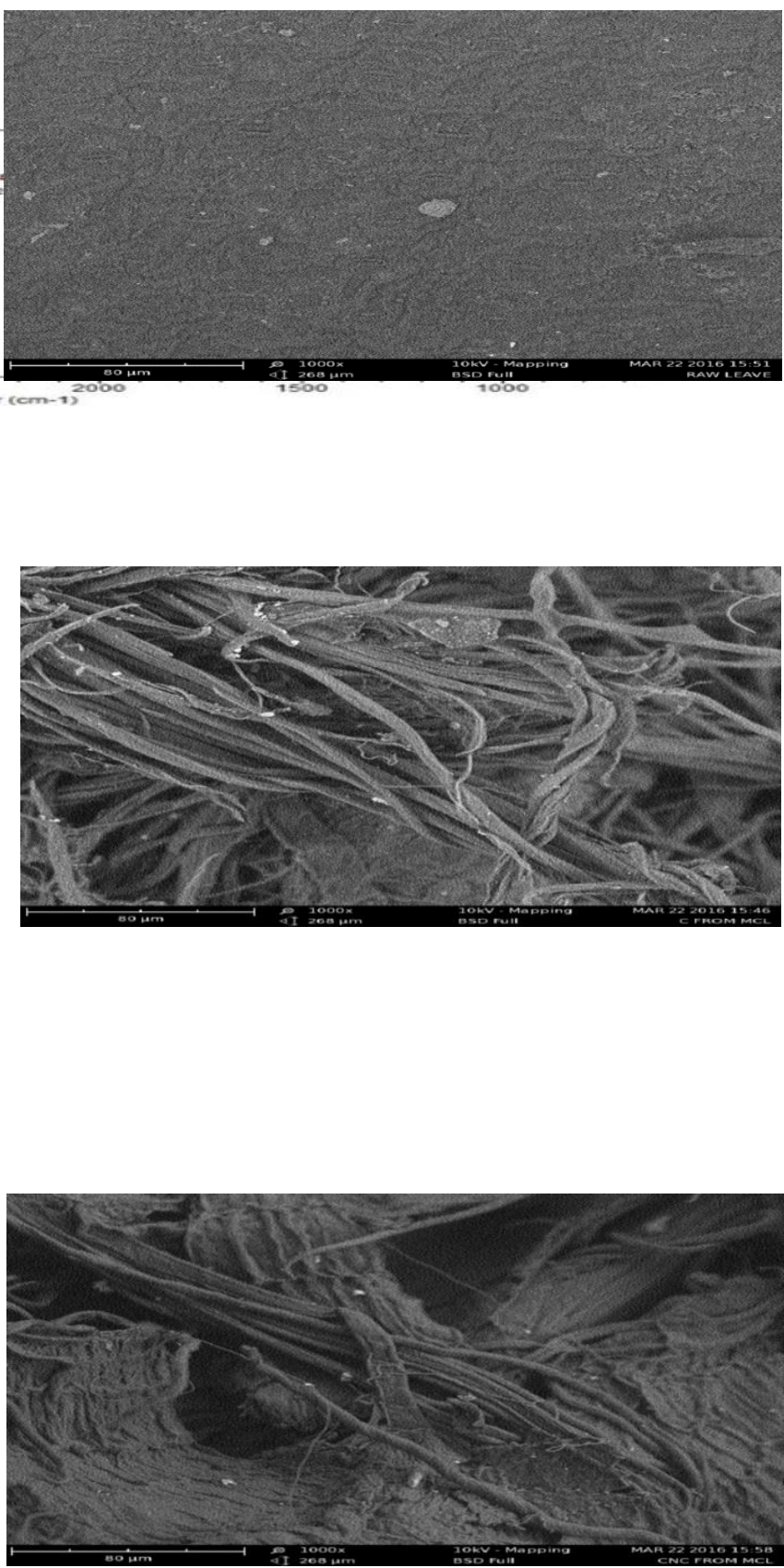

Figure 4a: SEM Image of Marantochloa cuspidata leaves.

Figure 4b: SEM Image of cellulose from Marantochloa cuspidata leaves.

Figure 4c: SEM Image of Microcrystalline cellulose from Marantochloa cuspidata leaves.

Micrographs of the raw leaf samples (Figure 4a), shows the raw leaf with unexposed cellulose fibres at magnifications of $1000 \mathrm{X}$ while the micrographs 
(Figure 4b), presents the treated samples with exposed microfibrils. The presence of the fibrils is an indication of the removal of the cementatious lignin material and the hemicellulose components of the native leaf sample. The fibrils are presented with a width to length ratio range between $80 \mu \mathrm{m}$ to $200 \mu \mathrm{m}$ (Figure 4c). The primary individual fibre presentation shows helicoidally structured strands which agrees with the natural ordered chains of cellulose. This structuring is as a result of the micro-ordered chains of pure native cellulose. This is investigative of the microcrystal nature of the extracted product. The microfibrils appear also as "spaghetti-like" clumps which is suggestive of their being crystallites.

\section{Thermogravimetric analyses}

The results of thermal analyses of raw leaves of Marantochloa cuspidata, cellulose and MCC are shown in Table 2, Figures 5a, b \& c.

Table 2: Degradation temperature for Marantochloa cuspidata leaves, cellulose and MCC

\begin{tabular}{ccc}
\hline Sample & $\begin{array}{c}\mathbf{1}^{\text {st }} \text { degradation } \\
\text { temp./weight } \\
\text { loss }\end{array}$ & $\begin{array}{c}\mathbf{2}^{\text {nd }} \text { degradation } \\
\text { temp./weight loss }\end{array}$ \\
\hline $\begin{array}{c}\text { Raw } \\
\text { leaves }\end{array}$ & $275-430^{\circ} \mathrm{C} / 65 \%$ & $430-620^{\circ} \mathrm{C} / 9 \%$ \\
Cellulose & $250-340^{\circ} \mathrm{C} / 80 \%$ & $340-650^{\circ} \mathrm{C} / 26 \%$ \\
MCC & $260-390^{\circ} \mathrm{C} / 92 \%$ & $390-620^{\circ} \mathrm{C} / 20 \%$ \\
\hline
\end{tabular}

An initial weight loss was observed from 50 to $100^{\circ} \mathrm{C}$ for all samples, caused by the gradual evaporation of residual moisture. The degradation behaviour of the MCC did not show significant difference from that of cellulose. Cellulose started to degrade at $250^{\circ} \mathrm{C}$, while MCC started to degrade at $260^{\circ} \mathrm{C}$ and the raw leaves at $275^{\circ} \mathrm{C}$.

\section{TGA/DTA}

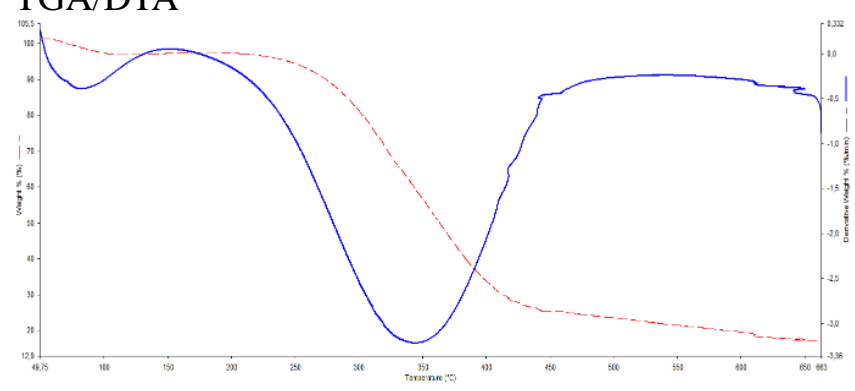

Figure 5a: TGA/DTA curves of Marantochloa cuspidata Leaves.

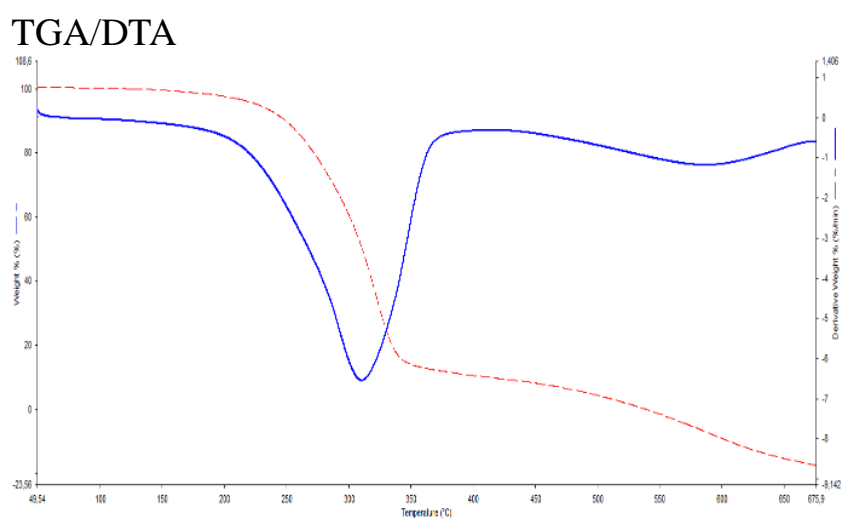

Figure 5b: TGA/DTA curves of cellulose from Marantochloa cuspidata leaves.

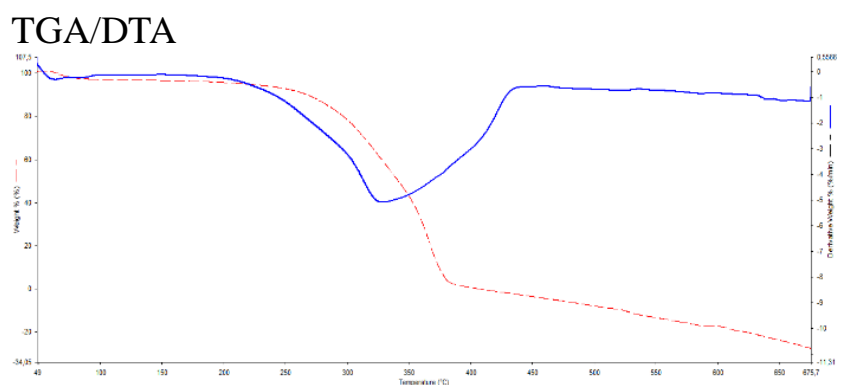

Figure 5c: TGA/DTA curves of MCC from Marantochloa cuspidata leaves.

\section{CONCLUSION}

In this study, cellulose and microcrystalline cellulose were successfully extracted from Marantochloa cuspidata leaves. From XRD analysis, intense peak was observed for MCC, indicating a higher crystallinity while for TGA, the degradation temperatures for extracted cellulose and MCC were moderate, specifically below $400^{\circ} \mathrm{C}$ as required for suitability for biocomposite processing.

\section{REFERENCES}

1. D. Klemm, B. Heublein, H.P. Fink and A. Bohn(2005). Cellulose: fascinating biopolymer and sustainable raw material. AngewandteChemieInternational Edition 44(22):3358-339.

2. D.G., Coffey, D. A. Bell and A.Henderson (1995). Food Polysaccharide and their application. Marcell Dekker, New York p83.

3. A. De Menezes Jr, G. Siqueira, A. A. Curvelo and A. Dusfresne (2009). Extraction and Characterization of functional cellulose whiskers reinforced polyethylene nanocomposites. Polymer 50:4552-4564. 
4. R. Li, J. Fe, Y. Cai, Y, Li, J. Feng and J. Yao (2009). Cellulose whiskers extracted from mulberry. A novel biomass production. Carbohydrate Polymer 76(1):94-99.

5. H.P., Fink, D. Hofmann, B Philipp, (1995). Some aspects of lateral chain order in cellulosics from $\mathrm{X}$-ray scattering. Cellulose 2:51-70.

6. W. Bai and K. Li (2009). Partial replacement of silica with microcrystalline cellulose in rubber composites. Composites Part A 40: 1597-1605H.

7. M.T. Arowona, G. A. Olatunji, O. D. Saliu, O. R. Adeniyi, O. Atolani and M. J. Adisa (2018). Thermally Stable Rice Husk Microcrystalline Cellulose as Adsorbent in PTLC Plates. JOTCSA 5(3): 1177

8. P. Lalduhsanga, D. C. Vanlalfakawma, S. K. Tripathi and H. Lalhlenmawia (2014). Muli bamboo (Melocanna baccifera) as a new source of microcrystalline cellulose. Journal of Applied Pharmaceutical Science 4(11):087-094.

9. P. M. Ejikeme (2008). Investigation of the Physicochemical Properties of Microcrystalline Cellulose From Agricultural Wastes I: Orange Mesocarp. Cellulose 15(1):141-147.
10. A. Ilindra and J. D. Dhake (2008.) Microcrystalline cellulose from bagasse and rice straw Indian Journal of Chemical Technology 15:97-499

11. M. I. Maha, K. E. Waleed, J. Yvonne and T. Heinze (2013). Cellulose and microcrystalline cellulose from rice straw and banana plant waste: Cellulose 20(5)DOI: 10.1007/s10570-013-9992-5

12. T. Zhao, Z. Chen, X. Lin, Z. Ren, B. Li and Y. Zhang (2018). Preparation and characterization of microcrystalline cellulose (MCC) from tea waste. Carbohydrate polymer $184: 164-170$

13. M. K. Haafiz, S. J. Eichlion A.M. Hassan and M. Jawaid (2013). Microcrystalline cellulose from oil palm biomass residue. Carbohydrate polymers 93(2):628-634.

14. R. K. Wiwin, I. L.Isa and H. Iyabu, (2018). FTIR, XRD and SEM Analysis of Microcrystalline Cellulose (MCC) Fibers from Corncorbs in Alkaline Treatment. Journal of Physics Conf. series.1028 DOI:10.1088/1742-6596/1028/1/012199

15. L. Segal, J. J. Creely, A.E. Martin and C. M. Conrad (1959). An empirical method for estimating the degree of crystallinity of native cellulose using the X-ray diffractometer. Textile Research Journal 29(10):786-794. 